\title{
A HILIC Mechanism Discussion for the Retention of HP- $\beta$-CD
}

\author{
Jianqiang Wei ${ }^{1}$, Hui Wang ${ }^{2 *}$, Song $\mathrm{Wu}^{3}$ \\ ${ }^{1}$ Zhengzhou Tongtai Medical Science \& Technology Co., Ltd., Zhengzhou, China \\ ${ }^{2}$ Henan Province Health Albert Biomedical Research Co., Ltd, Zhengzhou, China \\ ${ }^{3}$ Institute of Materia Medica, Chinese Academy of Medical Sciences \& Peking Union Medical College, Beijing, \\ China \\ Email: *whwang163@126.com
}

Received 25 April 2014; revised 6 June 2014; accepted 16 July 2014

Copyright (C) 2014 by authors and OALib.

This work is licensed under the Creative Commons Attribution International License (CC BY).

http://creativecommons.org/licenses/by/4.0/

(c) (i) Open Access

\begin{abstract}
A hydrophilic interaction liquid chromatography (HILIC) method coupled with a refractive index (RI) detector was developed for the determination of hydroxypropyl- $\beta$-cyclodextrin (HP- $\beta$-CD). This HILIC method used simple acetonitrile/water $(80 / 20, \mathrm{v} / \mathrm{v})$ as the mobile phase to provide sufficient retention for HP- $\beta$-CD. The method was found to be specific without interference from the other constituents in pharmaceutics. The method was also validated for linearity and accuracy of the drug sample. The effects of various parameters, such as acetonitrile content, mobile phase pH, and column temperature on HILIC analysis were investigated. Furthermore, the retention mechanism was assessed by the evaluation of the common chromatographic parameters.
\end{abstract}

\section{Keywords}

Hydroxypropyl- $\beta$-Cyclodextrin, Quantitative Analysis, Pinocembrin, HILIC

Subject Areas: Analytical Chemistry

\section{Introduction}

Hydroxypropyl- $\beta$-cyclodextrin is a cyclic oligosaccharide, made up of seven $D$-glucopyranose units linked by $\alpha$-1,4-glycosidic bonds. Owing to its configuration, it has a cylinder-shaped, electron-rich, internal hydrophobic cavity and a hydrophilic external surface. The lipophilic cavity enables HP- $\beta$-CD to form non-covalent inclusion complexes with a wide variety of poorly water-soluble compounds in aqueous solutions by the spatial entrapment of a whole molecule, or at least some part of it, into the cavity [1] or in a channel formed by several molecules of HP- $\beta$-CD, whereas the hydrophilic outer surface renders these inclusion complexes water soluble. In

\footnotetext{
${ }^{*}$ Corresponding author.
} 
addition, inclusion of molecules within the cavity of HP- $\beta$-CD may protect the guest from the external environment, and hence, HP- $\beta$-CD may be used to optimize the chemical stability of molecules susceptible to degradation [1]. Such molecular encapsulation has been shown to improve a variety of drug properties, such as chemical stability, solubility, dissolution rate, bioavailability and clinical activity [1] [2]. Due to its better amorphous nature, higher water solubility ( $>1 \mathrm{~g} / \mathrm{mL}$ ), higher inclusion affinity, lower toxicity, and greater ability to alter the phase solubility behavior [3] [4] than other cyclodextrins, HP- $\beta$-CD has been more widely used in the development of pharmaceuticals.

Although more useful in pharmacy, the toxic side effects of HP- $\beta$-CD have also been cautiously studied, especially in overdose. To date, the US Food and Drug Administration (FDA) has only approved the application of HP- $\beta$-CD in itraconazole injection and long-acting levonorgestrel subcutaneous implants. As a pharmaceutical excipient, more than $90 \%$ of HP- $\beta$-CD is metabolized in the kidney after the drug is injected into the body, thus, thetoxic side effects need to be considered. Some experiments have indicated that the use of excessive HP- $\beta$-CD can lead to renal toxicity, hemolysis and even cancer [5]. In a 2-year rat carcinogenicity study, the high-dose intravenous injection of HP- $\beta$-CD led to exocrine pancreatic hyperplasia in 12 months and then developed to exocrine pancreatic neoplasia by 24 months. Therefore, it is necessary to develop a more efficient and robust method for the quantitative determination of HP- $\beta$-CD.

It has been shown that HP- $\beta$-CD can be quantified from the molar substitution using NMR [6], however, this method can not be widely used for the determination of HP- $\beta$-CD in its inclusion complex because of a lack of special instruments. Moreover, the other constituents in pharmaceutics can interfere with the analysis of HP- $\beta$ CD content. Herein, we established a hydrophilic interaction liquid chromatography (HILIC) method to solve these problems. This mode of chromatography has been used for the separation of highly polar substances including biologically active compounds, such as drugs, neurotransmitters, nucleosides, nucleotides, amino acids, peptides, proteins, oligosaccharides, and carbohydrates [7]-[10].

In this work, a HILIC approach and mechanism had been established and discussed with a refractive index (RI) detector. And then the method was applied to determine the HP- $\beta$-CD as a pharmaceutical adjuvant in a powder formulation of pinocembrin, which was developed by our institute to treat cerebral ischemia.

\section{Experimental}

The experiments were performed on an Agilent 1200 HPLC system equipped with both a diode array (DAD, Model G1315D) and refractive index (RI, Model G1362A) detector (Agilent Technologies, Palo Alto, CA. USA). HPLC grade acetonitrile, methanol and isopropanol were purchased from Merck (Merck KGaA, Germany). Ammonium acetate (HPLC grade) was purchased from Mreda (Mreda Technology Inc., USA). HP- $\beta$-CD (pharmaceutical grade) was purchased from Deli (Xi’an Deli Biological Chemical Co., Ltd.). Deionized water, pinocembrin (5,7-dihydroxy flavanone) and its powder formulation (an inclusion complex which contains pinocembrin: HP- $\beta$-CD, 10:100, w/w) were produced in our laboratory.

The HILIC column (Alltima HP HILIC, $250 \times 4.6 \mathrm{~mm}$ I.D. with $5 \mu \mathrm{m}$ particles, from Alltech Technologies) was used as solid phase and acetonitrile/water (80/20, v/v) as mobile phase. The flow rate was $1.5 \mathrm{~mL} / \mathrm{min}$ and the column temperature was kept at $35^{\circ} \mathrm{C}$. The detection limit at an injection volume of $20 \mu \mathrm{l}$ was $0.05 \mathrm{mg} / \mathrm{ml}$. All the standards and samples described were dissolved in the mobile phase. The optical unit temperature of the $\mathrm{RI}$ detector was set at $35^{\circ} \mathrm{C}$ to minimize the baseline noise.

\section{Result and Discussion}

Contrary to normal phase HPLC, the mobile phase used in HILIC was similar to that in reverse-phase HPLC. Aqueous-organic mixtures were used as mobile phases, however, water was considered to be the strongest eluent and increasing water content in the mobile phase led to a shorter retention time for polar analytes in the HILIC analysis.

The effect of water content (50\% - 10\%) in the mobile phase on retention is shown in Figure 1. No retention was obtained for HP- $\beta$-CD under $50 \%$ and $10 \%$ water content. As the water content decreased, the retention time increased and the peak became wider. It can be seen in Figure 2(b) that the value of $\ln k^{\prime}$, in the water content range of $40 \%-10 \%$ increased in a linear fashion. It is possible that the water phase molecules firstly combined in the stationary phase, then the HP- $\beta$-CD molecules conjugated with the water molecules, and the polar analytes were then retained and eluted by the aqueous-organic mobile phase. When the water content in- 


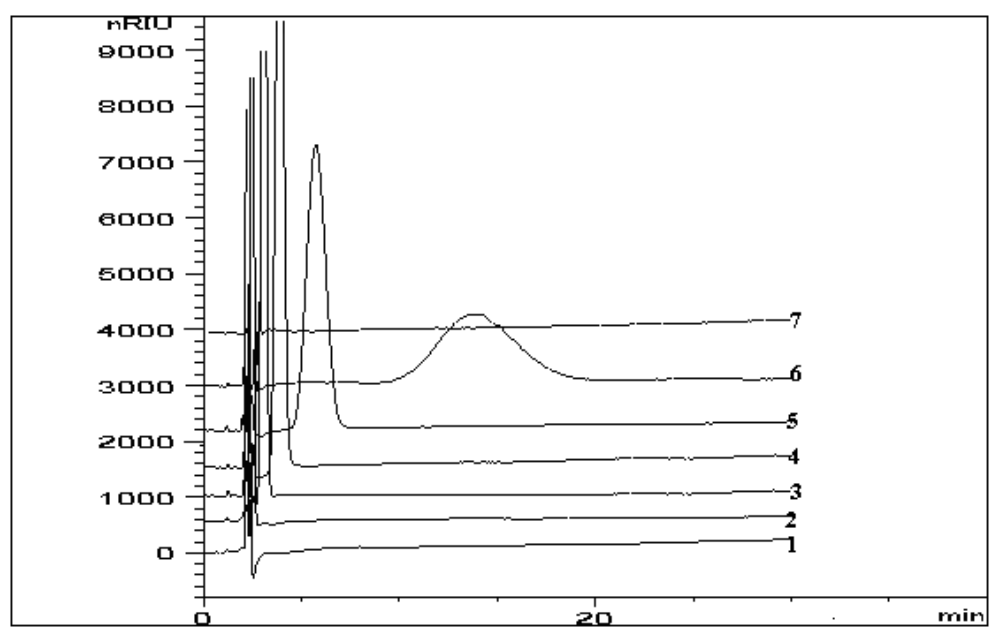

Figure 1. Chromatograms of different water contents in the mobile phase: (1) $50 \%$ water, (2) $40 \%$ water, (3) $30 \%$ water, (4) $25 \%$ water, (5) $20 \%$ water, (6) $15 \%$ water, (7) $10 \%$ water. Column temperature: $35^{\circ} \mathrm{C}$. Flow rate: $1.5 \mathrm{~mL} /$ min. Sample: HP- $\beta$-CD $(3.0 \mathrm{mg} / \mathrm{mL})$ dissolved in the mobile phase. Injection volume: $20 \mu \mathrm{L}$.

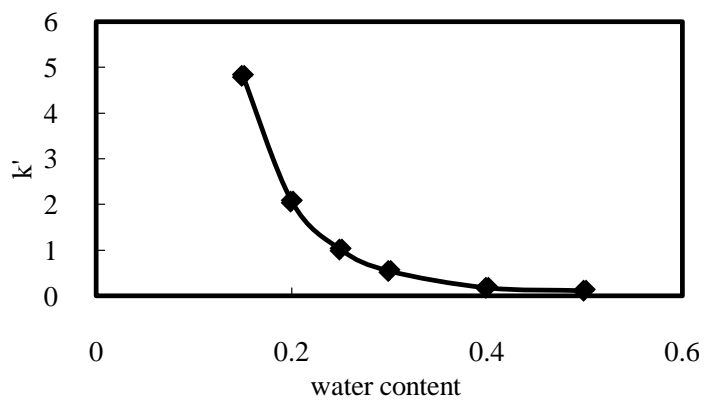

(a)

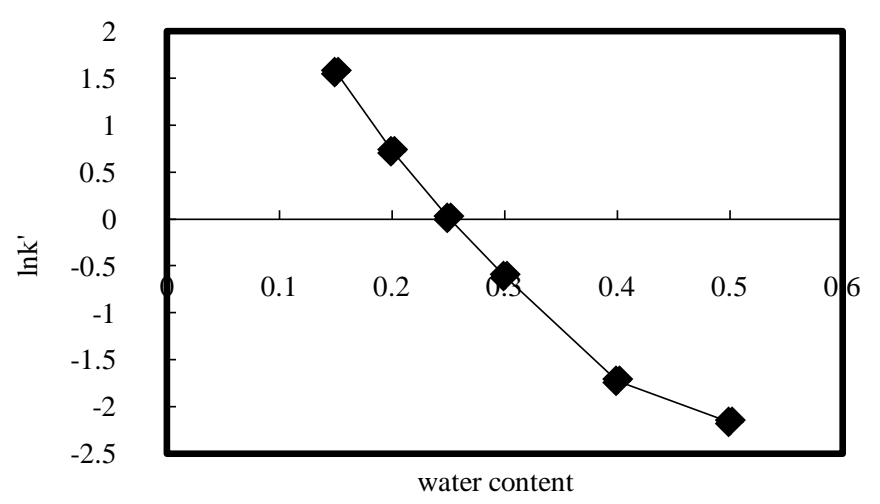

(b)

Figure 2. (a) Plot of retention factor $\left(k^{\prime}\right)$ versus the content of water in the mobile phase. (b) Plot of $\ln k^{\prime}$ versus the content of water in the mobile phase. Column temperature: $35^{\circ} \mathrm{C}$. Flow rate: $1.5 \mathrm{~mL} / \mathrm{min}$. Sample: HP- $\beta$-CD $(3.0 \mathrm{mg} / \mathrm{mL})$ dissolved in the mobile phase. Injection volume: $20 \mu \mathrm{L}$.

creased to 50\%, the $\ln k^{\prime}$ value deviated from linearity, which could have been due to a concomitant mechanism: when the water content increased beyond a certain level (50\% in this experiment), an interaction between the water and the analytes within the mobile phase could have occurred. Thus, a restricted range for linearity existed, and 20\% water content was used in subsequent experiments.

The $\mathrm{pH}$ value of the mobile phase is usually considered to be an important factor in obtaining favorable peak symmetries. Ammonium acetate/acetic acid, due to its good solubility at high organic content, were used in this experiment. The effect of $\mathrm{pH}$ in the water phase was studied in the $\mathrm{pH}$ range of 3.0 - 6.5. As shown in Figure 3, when $\mathrm{pH}$ increased, the retention time of HP- $\beta$-CD increased very slightly, and the peak symmetry showed little improvement. Compared with the elution without buffer, we can conclude that there were insignificant changes in the presence of buffer. Base on chromatography without buffer (Figure 3 plot 5), it can be seen that the retention was acceptable and the peak showed good form and symmetry. Compared with plot 5, there was little change in the elution with buffer. Thus, buffer was excluded due to its lack of effect on these analytes.

Column temperature is also an important parameter that affects the retention and separation of analytes in HILIC [11] [12]. The effect of column temperature was studied using the Van't Hoff equation, which is often used to describe the relationship between the capacity factor $\left(k^{\prime}\right)$ and column temperature $(T)$ : 


$$
\ln k^{\prime}=-\frac{\Delta H^{\circ}}{R T}+\frac{\Delta S^{\circ}}{R}+\ln \phi
$$

where $\Delta H^{\circ}$ and $\Delta S^{\circ}$ are the change in enthalpy and entropy of the analytes, respectively. $R$ is the gas constant and $\phi$ the phase ratio. The effect of column temperature on the retention of HP- $\beta$-CD was assessed in the temperature range of $15^{\circ} \mathrm{C}-60^{\circ} \mathrm{C}$. As shown in Figure 4, at temperatures below $50^{\circ} \mathrm{C}$, the value of $\ln k^{\prime}$ decreased when the temperature increased (Figure 4(b)), and in the temperature range of $15^{\circ} \mathrm{C}-50^{\circ} \mathrm{C}$ (plot b), the Van't Hoff plot was linear $\left(R^{2}>0.99\right)$ and had a positive slope. However, when the temperature was above $50^{\circ} \mathrm{C}$ (Figure 4(a)), the $\ln k^{\prime}$ decreased significantly and tended to level. The calculated enthalpy value $\left(-\Delta H^{\circ}\right)$ was about $12.1 \mathrm{KJ} / \mathrm{mol}$ for $\mathrm{HP}-\beta$-CD in the linear range and $2.2 \mathrm{KJ} / \mathrm{mol}$ in the horizontal range. Clearly, when the temperature reached a certain range, $\ln k^{\prime}$ changed little.

The method precision for HP- $\beta$-CD was established using six target concentrations which yielded a relative standard deviation (\% RSD) of $0.8 \%$. The calibration curve of HP- $\beta$-CD was linear from 0.1 to $7.0 \mathrm{mg} / \mathrm{mL}$ with correlation coefficient of $R^{2}>0.99$. The detection limit was $0.05 \mathrm{mg} / \mathrm{mL}(S / N=3)$ which is enough for the determination of HP- $\beta$-CD in pinocembrin powder formulation.

During the quantitative analysis of HP- $\beta$-CD in pinocembrin, the specificity was demonstrated by DAD connected with RID in series. The pinocembrin eluted early on the HILIC column and did not interfere with the HP$\beta$-CD determination.

The recovery was performed for the components at the level of $80 \%, 100 \%$ and $120 \%$ of the assay target concentrations. The results for HP- $\beta$-CD recovery were $101.4 \%, 100.3 \%$ and $100.1 \%$ with a RSD\% of $0.7 \%$.

The content of HP- $\beta$-CD in three batches of pinocembrin powder formulation is shown in Table 1.

\section{Conclusion}

In this work, we established an HILIC method with a RI detector to determine HP- $\beta$-CD and applied this optimized method for the analysis of HP- $\beta$-CD in pinocembrin powder formulation. The method linearity was in the range of $0.1-7.0 \mathrm{mg} / \mathrm{ml}\left(R^{2}>0.99\right)$. A relative standard deviation (RSD) of $0.8 \%(N=9)$ demonstrated good precision of the optimized method. In addition, the results showed that, under the optimized HILIC conditions, HP- $\beta$-CD had an appropriate retention time and could be analyzed in the formulation, which could be used to control HP- $\beta$-CD quantification in pinocembrin preparations. Thus, this HILIC method could provide a new approach for the analysis of HP- $\beta$-CD, even in pharmaceutical preparations containing HP- $\beta$-CD.

\section{Acknowledgements}

This work was financially supported by Major Scientific and Technological Special Project for "Significant

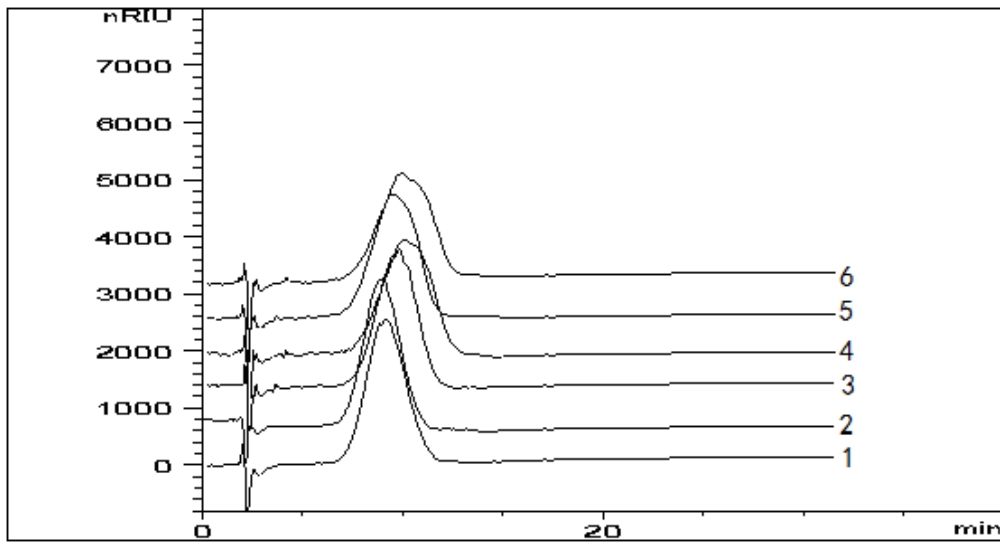

Figure 3. Chromatograms at different $\mathrm{pH}: 1-\mathrm{pH}=3.0,2-\mathrm{pH}=4.0,3-\mathrm{pH}$ $=5.0,4-\mathrm{pH}=5.5,5-\mathrm{pH}=6.0,6-\mathrm{pH}=6.5$. Column temperature: $35^{\circ} \mathrm{C}$. Mobile phase: acetonitrile/water with buffer $(80 / 20, \mathrm{v} / \mathrm{v})$. Flow rate: 1.5 $\mathrm{mL} / \mathrm{min}$. Sample: HP- $\beta$-CD $(3.0 \mathrm{mg} / \mathrm{mL})$ dissolved in the mobile phase. Injection volume: $20 \mu \mathrm{L}$. 


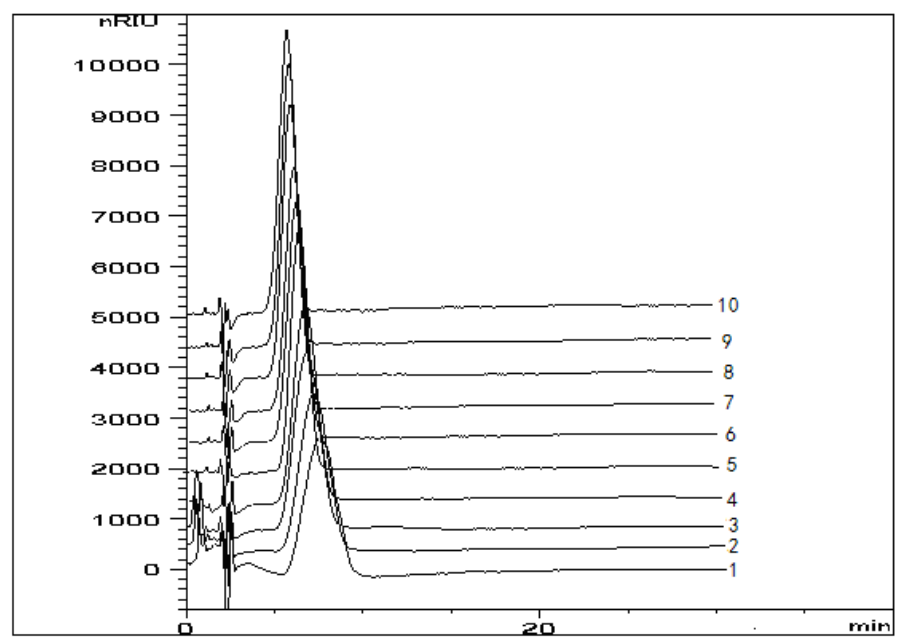

(a)

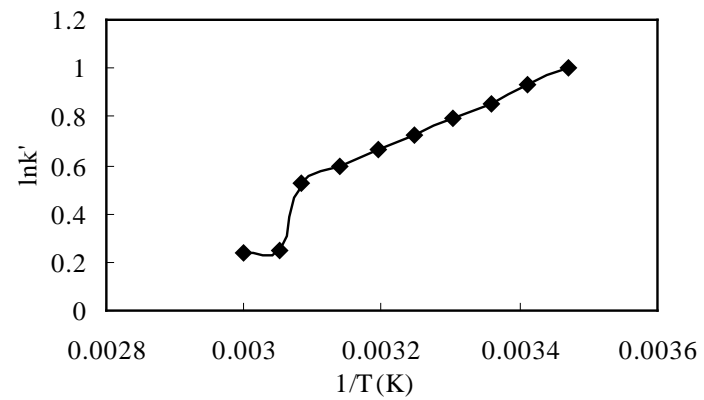

(b)

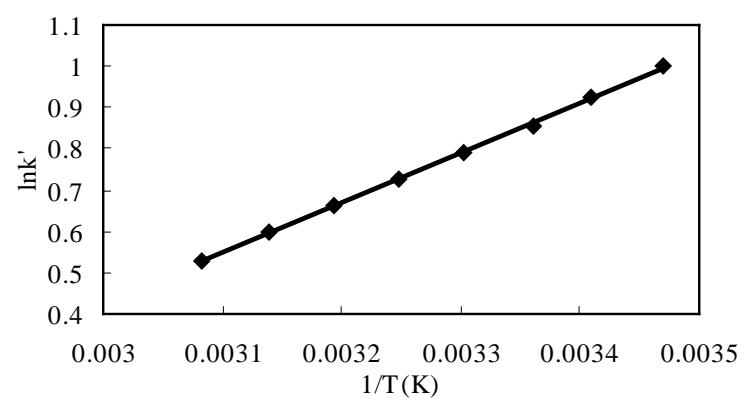

(c)

Figure 4. Effect of column temperature on the retention of $\mathrm{HP}-\beta$-CD. (a) $1-15^{\circ} \mathrm{C}, 2-20^{\circ} \mathrm{C}, 3-25^{\circ} \mathrm{C}, 4-30^{\circ} \mathrm{C}, 5-35^{\circ} \mathrm{C}, 6$ $-40^{\circ} \mathrm{C}, 7-45^{\circ} \mathrm{C}, 8-50^{\circ} \mathrm{C}, 9-55^{\circ} \mathrm{C}, 10-60^{\circ} \mathrm{C}$. (b) Plot of $\ln k^{\prime}$ versus the column temperature in the range of $15^{\circ} \mathrm{C}-60^{\circ} \mathrm{C}$. (c) Plot of $\ln k^{\prime}$ versus the column temperature in the range of $15^{\circ} \mathrm{C}-50^{\circ} \mathrm{C}, R^{2}>0.99$. Mobile phase: acetonitrile/water (80/20, v/v). Flow rate: $1.5 \mathrm{~mL} / \mathrm{min}$. Sample: HP- $\beta$-CD $(3.0 \mathrm{mg} / \mathrm{mL})$ dissolved in the mobile phase. Injection volume: $20 \mu \mathrm{L}$.

Table 1. Pinocembrin sample determination.

\begin{tabular}{ccc}
\hline Sample & Sample weight (mg) & HP- $\beta$-CD content (\%) \\
\hline Medicine sample 1 & 32.8 & 99.35 \\
Medicine sample 2 & 33.2 & 99.77 \\
Medicine sample 3 & 33.1 & 99.76
\end{tabular}

New Drugs Innovation” (2013ZX09402103).

\section{References}

[1] Lôftsson, T. and Brewster, M.E. (1996) Pharmaceutical Applications of Cyclodextrins. 1. Drug Solubilization and Stabilization. Journal of Pharmaceutical Sciences, 85, 1017-1025. http://dx.doi.org/10.1021/js950534b

[2] Wong, J.W. and Yuen, K.H. (2001) Improved Oral Bioavailability of Artemisinin through Inclusion Complexation with Beat- and Gama-Cyclodextrins. International Journal of Pharmaceutics, 227, 177-185. http://dx.doi.org/10.1016/S0378-5173(01)00796-7

[3] Choi, H.G., Kim, D.D., Jun, H.W., Yoo, B.K. and Yong, C.S. (2003) Improvement of Dissolution and Bioavailability of Nitrendipine Byinclusion in Hydroxypropyl $\beta$-Cyclodextrin. Drug Development and Industrial Pharmacy, 29, 10851094.

[4] Slain, D., Rogers, P.D., Chapman, S.W. and Cleary, J.D. (2001) Intravenous Itraconazole: A Formulary Focus. Annales Pharmaceutiques Françaises, 35, 720-729. 
[5] Gould, S. and Scott, R.C. (2005) 2-Hydroxypropyl-beta-Cyclodextrin (HP-beta-CD): A Toxicology Review. Food and Chemical Toxicology, 43, 1451-1459. http://dx.doi.org/10.1016/j.fct.2005.03.007

[6] European Pharmacopoeia. 5th Edition, 1771.

[7] Ikegami, T., Tomomastu, K., Takubo, H., Horie, K. and Tanaka, N. (2008) Separation Efficiencies in Hydrophilic Interaction Chromatography. Journal of Chromatography A, 1184, 474-503. http://dx.doi.org/10.1016/j.chroma.2008.01.075

[8] Liu, M., Chen, E. X., Ji, R. and Semin, D. (2008) Stability-Indicating Hydrophilic Interaction Liquid Chromatography Method for Highly Polar and Basic Compounds. Journal of Chromatography A, 1188, 255-263. http://dx.doi.org/10.1016/j.chroma.2008.02.071

[9] Zhou, T. and Lucy, C.A. (2008) Hydrophilic Interaction Chromatography of Nucleotides and Their Pathway Intermediates on Titania. Journal of Chromatography A, 1187, 87-93. http://dx.doi.org/10.1016/j.chroma.2008.02.027

[10] Yoshida, T. (2004) Peptide Separation by Hydrophilic-Interaction Chromatography: A Review. Journal of Biochemical and Biophysical Methods, 60, 265-280. http://dx.doi.org/10.1016/j.jbbm.2004.01.006

[11] Guo, Y. and Huang, A.H. (2003) A HILIC Method for the Analysis of Tromethamine as the Counter Ion in an Investigational Pharmaceutical Salt. Journal of Pharmaceutical and Biomedical Analysis, 31, 1191-1201. http://dx.doi.org/10.1016/S0731-7085(03)00021-9

[12] Hao, Z.G., Lu, C.Y., Xiao, B., Weng, N.D., Parker, B., Knapp, M. and Ho, C.T. (2007) Separation of Amino Acids, Peptides and Corresponding Amadori Compounds on a Silica Column at Elevated Temperature. Journal of Chromatography A, 1147, 165-171. http://dx.doi.org/10.1016/j.chroma.2007.02.057 